Dokuz Eylul University, serife.faydaoglu@deu.edu.tr, Izmir-Turkey

http://dx.doi.org/10.12739/NWSA.2017.12.1.3A0078

\title{
APPROXIMATE SOLUTIONS OF NONLINEAR OSCILLATORS
}

\section{ABSTRACT}

The modified homotopy perturbation method (MHPM) is used for solving the differential equation of pendulum model. Comparisons are made between the standard HPM and the MHPM. The results show that this method is effective and can obtain high accuracy solutions by only one iteration.

Keywords: Nonlinear Oscillators, Homotopy Perturbation Method, Modified Homotopy Perturbation Method, Simple

Pendulum, Approximate Solutions

\section{LINEER OLMAYAN OSİLATÖRLERIN YAKLAŞIK ÇÖZÜMLERİ}

\section{Öz}

Sarkaç modelinin diferansiyel denkleminin çözümü için değiştirilmiş Homotopi perturbasyon yöntemi kullanılıyor. Standart homotopi ve değiştirilmiş homotopi yöntemi arasında karşılaştırmalar yapılıyor. Sonuçlar bu yöntemin etkin olduğunu ve sadece bir iterasyon ile yüksek hassas çözümler elde edilebileceğini gösteriyor.

Anahtar Kelimeler: Doğrusal Olmayan Osilatörler, Homotopi Perturbasyon Yöntemi, Değiştirilmiş Homotopi Perturbasyon Yöntemi, Basit Sarkaç, Yaklaşık Çözümler 


\section{INTRODUCTION}

Nonlinear oscillators are important in physical sciences; engineering and the other disciplines. It is difficult to solve them analytically. Recently, an extensive attention has been directed to analytical and numerical solutions of these class of problems. The homotopy perturbation method (HPM) is a powerful technique for solving nonlinear problems. The HPM was introduced by He [1 and 2]. Generally, this method leads to accurate approximation by using one iteration only. The HPM combines the traditional perturbation method and the homotopy in topology. It does not require a small parameter in an equation. This property of HPM has a significant advantage in many nonlineaar problems. Recently, researchers apply methods which do not require small parameters. For example, He's homotopy perturbation method [3, 4, 5, 6, 7, 8 and 9], parameter-expansion method [10 and 11] variational iteration method [12 and 13], modified LindstedtPoincaré method [14], rational harmonic balance method [15], Adomian decomposition method [16], method of energy balance [17]. In last decades, some modifications of HPM are investigated to facilitate and accurate the calculation and acceleration of the rapid convergence of the series solution $[18,19,20,21,22$ and 23]. In this paper, the modified homotopy perturbation method has been applied for solving a nonlinear differential equation. Moreover, the comparison with the HPM has been done. The solutions obtained by this method have been presented in graphs.

\section{RESEARCH SIGNIFICANCE}

The mathematical pendulum equation has been solved by HPM and MHPM. The comparison of these methods is presented in the paper.

\section{ANALYTICAL STUDY}

Our work is based on applied mathematics. Practical applications in science, engineering and industry have motivated the development of mathematical theories, which then became the subject of study in pure mathematics. Therefore we deduce mathematical methods to solve the nonlinear equations by means of analysis of method $[18,19,20,21$, 22,23 and 24].

\section{THE MODIFICATION OF HPM}

The modified homotopy perturbation method that is used to solve the nonlinear oscillator is similar to standard HPM. To make the modification, we add and subtract a linear term such as $f(A)$ to the main governing equation and then apply the linearization. In this way, the governing equation remain unchanged, but we choose just one of the additional terms for using in linear operator. This term which is added to linear operator, prevents the solution from divergence and it causes the rapid convergent and much accurate solution. The only difference between present HPM and standard HPM is the linear operator, and the other procedures are the same. In the modified form, linear operator plays the important role in solution. To demonstrate the effectiveness of the proposed modification and to compare the new modification of the HPM with the standard HPM, we have chosen the following the nonlinear equation.

\section{APPLICATION}

Let us consider the differential equation modeling the free undamped simple pendulum [17],

$$
u^{\prime \prime}+\alpha^{2} \sin u=0,
$$

with initial conditions, 
$u(0)=A, \quad u^{\prime}(0)=0$.

Where $\boldsymbol{u}$ is the angular displacement, $\boldsymbol{\alpha}=\sqrt{\boldsymbol{g} / \boldsymbol{1}}, \boldsymbol{g}$ is the length of the pendulum and $\boldsymbol{I}$ is the acceleration due to gravity. $\boldsymbol{A}$ is the amplitude of the oscillation. To apply the modified homotopy perturbation method, we introduce the additional term as $f(A)$ for (1). Here $A$ comes from the initial condition. We choose an additional term function of boundary conditions. In this way we have such studies in ref. $[18,19,20,21,22$ and 23].

$$
u^{\prime \prime}+f(A) u-f(A) u+0 . u+\alpha^{2}\left(u-\frac{u^{3}}{6}-\frac{u^{5}}{120}\right)=0,
$$

Here $\sin u \approx u-\frac{\mathbf{u}^{3}}{6}-\frac{\mathbf{u}^{5}}{120}$. Now, we consider just one of the additional terms for linear operator:

$L(u): \equiv u^{\prime \prime}+f(A) u+0 . u$

If we consider the solution as

$u=\sum_{k=0}^{n} \beta_{k} e^{c_{k} t}$

and expansion the zero as

$0=\mathbf{w}^{2}+\sum_{k=1}^{n} \beta_{k} \mathbf{w}_{k}$

and substitute to the characteristic equation of governing equation, we have:

$$
\begin{gathered}
c_{k}^{2}\left(\sum_{k=0}^{n} \beta_{k} e^{c_{k} t}\right)+\left(w^{2}+\sum_{k=1}^{n} \beta_{k} w_{k}\right)\left(\sum_{k=0}^{n} \beta_{k} e^{c_{k} t}\right)+\alpha^{2}\left[\left(\sum_{k=0}^{n} \beta_{k} e^{c_{k} t}\right)\right. \\
\left.-\frac{1}{6}\left(\sum_{k=0}^{n} \beta_{k} e^{c_{k} t}\right)^{3}+\frac{1}{120}\left(\sum_{k=0}^{n} \beta_{k} e^{c_{k} t}\right)^{5}\right]=0 .
\end{gathered}
$$

With considering $\mathbf{u}=\left(\sum_{\boldsymbol{k}=0}^{n} \boldsymbol{\beta}_{\boldsymbol{k}} \boldsymbol{e}^{\boldsymbol{c}_{\boldsymbol{k}} t}\right) \neq 0$, it simplifies to:

$c_{k}^{2}=-\left(w^{2}+\sum_{k=1}^{n} \beta_{k} w_{k}\right)+\alpha^{2}\left[1-\frac{1}{6}\left(\sum_{k=0}^{n} \beta_{k} e^{c_{k} t}\right)^{2}+\frac{1}{120}\left(\sum_{k=0}^{n} \beta_{k} e^{c_{k} t}\right)^{4}\right]$.

On the other hand, we hope that the solution of (4) serves as a leading term, $u_{0}$, in the solution series. Hence, the equation satisfied by $u_{0}$ should be in the form

$$
\mathbf{u}_{0}^{\prime \prime}+\boldsymbol{f}(\boldsymbol{A}) \mathbf{u}_{0}+\mathbf{w}^{2} \mathbf{u}_{0}=0 \text {. }
$$

Characteristic equation of this equation is written as:

$$
\boldsymbol{c}_{0}^{2}=-\boldsymbol{f}(\boldsymbol{A})-\boldsymbol{w}^{2}
$$

From (8), we have

$\boldsymbol{c}_{0}^{2}=-\left(\boldsymbol{w}^{2}+\boldsymbol{\alpha}^{2}\left[1-\frac{1}{6}\left(\boldsymbol{\beta}_{0} \boldsymbol{e}^{\boldsymbol{c}_{0} \boldsymbol{t}}\right)^{2}+\frac{1}{120}\left(\boldsymbol{\beta}_{0} \boldsymbol{e}^{\boldsymbol{c}_{0} t}\right)^{4}\right]\right)$.

$u_{0}=\beta_{0} e^{c_{0} t}=A e^{c_{0} t}$

From (11), we have,

$\boldsymbol{c}_{0}^{2}=-\left(\boldsymbol{w}^{2}+\boldsymbol{\alpha}^{2}\left[1-\frac{1}{6}\left(\boldsymbol{A} \boldsymbol{e}^{\boldsymbol{c}_{0} t}\right)^{2}+\frac{1}{120}\left(\boldsymbol{A} \boldsymbol{e}^{\boldsymbol{c}_{0} t}\right)^{4}\right]\right)$. 
Hence, from (10) and (13), we have:

$\boldsymbol{f}(\boldsymbol{A})=\boldsymbol{\alpha}^{2}\left[1-\frac{1}{6}\left(\boldsymbol{\beta}_{0} \boldsymbol{e}^{c_{0} t}\right)^{2}+\frac{1}{120}\left(\boldsymbol{\beta}_{0} \boldsymbol{e}^{c_{0} t}\right)^{4}\right]$

Because $f(A)$ is an integral number, thus we have

$|\boldsymbol{f}(\boldsymbol{A})|=\left|\boldsymbol{\alpha}^{2}\left[1-\frac{1}{6}\left(\boldsymbol{\beta}_{0} \boldsymbol{e}^{\boldsymbol{c}_{0} t}\right)^{2}+\frac{1}{120}\left(\boldsymbol{\beta}_{0} \boldsymbol{e}^{\boldsymbol{c}_{0} \boldsymbol{t}}\right)^{4}\right]\right|=\boldsymbol{\alpha}^{2}\left(1+\frac{\boldsymbol{A}^{2}}{6}+\frac{\boldsymbol{A}^{4}}{120}\right)$.

In view of the (5) and (15), we have:

$$
\begin{gathered}
\left.u^{\prime \prime}+\left[\alpha^{2}\left(1+\frac{A^{2}}{6}+\frac{A^{4}}{120}\right)+0\right] u-\alpha^{2}\left(1+\frac{A^{2}}{6}+\frac{A^{4}}{120}\right)+0\right] u \\
+p \alpha^{2}\left(u-\frac{u^{3}}{6}+\frac{u^{5}}{120}\right)=0
\end{gathered}
$$

We construct the following homotopy and consider the linear term as $\mathbf{u}^{\prime \prime}+\left[\boldsymbol{\alpha}^{2}\left(1+\frac{\boldsymbol{A}^{2}}{6}+\frac{\boldsymbol{A}^{4}}{120}\right)+0\right] \mathbf{u}:$

$u^{\prime \prime}+\left[\alpha^{2}\left(1+\frac{A^{2}}{6}+\frac{A^{4}}{120}\right)+0\right] u+p \alpha^{2}\left(u-\frac{u^{3}}{6}+\frac{u^{5}}{120}\right)=0$.

Substituting (5), (6) and the initial conditions (2) into the homotopy (17) and equating the terms with identical powers of $p$, we obtain the following set of linear differential equations:

$$
\begin{aligned}
& p^{0}: u_{0}^{\prime \prime}+w^{2} u_{0}+\alpha^{2}\left(1+\frac{A^{2}}{6}+\frac{A^{4}}{120}\right)=0, \quad u_{0}(0)=A, \quad u_{0}^{\prime}(0)=0 \\
& p^{1}: u_{1}^{\prime \prime}+w^{2} u_{1}+w_{1} u_{0}+\alpha^{2}\left(1+\frac{A^{2}}{6}+\frac{A^{4}}{120}\right) u_{1}+\alpha^{2}\left(u_{0}-\frac{u_{0}^{3}}{6}+\frac{u_{0}^{5}}{120}\right)=0, \\
& u_{1}(0)=0, \quad u_{1}^{\prime}(0)=0
\end{aligned}
$$

Solving the equation (18) is derived as follows:

$u_{0}=\boldsymbol{A} \cos \left(\sqrt{\left.\mathbf{w}^{2}+\alpha^{2}\left(1+\frac{\boldsymbol{A}^{2}}{6}+\frac{\boldsymbol{A}^{4}}{120}\right) t\right)}\right.$.

For the first-order approximation we have $\boldsymbol{p}=1$

$0=\mathbf{w}^{2}+\boldsymbol{w}_{1}$.

Substituting (20) and (21) into Eq. (19) yields to:

$u_{1}^{\prime \prime}+w^{2} u_{1}+\alpha^{2}\left(1+\frac{A^{2}}{6}+\frac{A^{4}}{120}\right) u_{1}+A\left[-w^{2}+\alpha^{2}\left(1-\frac{A^{2}}{8}+\frac{A^{4}}{192}\right)\right] \cos (w K t)$

$-\boldsymbol{\alpha}^{2}\left(\frac{\boldsymbol{A}^{3}}{24}-\frac{\boldsymbol{A}^{5}}{384}\right) \cos (3 K t)+\boldsymbol{\alpha}^{2} \frac{\boldsymbol{A}^{5}}{1920} \cos (5 K t)=0$.

Where $\boldsymbol{K}=\sqrt{\mathbf{w}^{2}+\boldsymbol{\alpha}^{2}\left(1+\frac{\boldsymbol{A}^{2}}{6}+\frac{\boldsymbol{A}^{4}}{120}\right.} \cdot$ Eliminating the seculaer term, we have

$u_{1}^{\prime \prime}+w^{2} u_{1}+\alpha^{2}\left(1+\frac{A^{2}}{6}+\frac{A^{4}}{120}\right) u_{1}-\alpha^{2}\left(\frac{A^{3}}{24}-\frac{A^{5}}{384}\right) \cos (3 K t)+\alpha^{2} \frac{A^{5}}{1920} \cos (5 K t)=0$. 
From the equation (23), we can find

$\boldsymbol{w}=\alpha\left(1-\frac{\boldsymbol{A}^{2}}{8}+\frac{\boldsymbol{A}^{4}}{192}\right)$.

According to Eqs. (23) and (24), we obtain the solution

$$
\mathbf{u}_{1}=\frac{\boldsymbol{\alpha}^{2} \boldsymbol{A}^{3}\left[-16\left(\boldsymbol{A}^{2}-15\right) \cos (\boldsymbol{K} t)+15\left(\boldsymbol{A}^{2}-16\right) \cos (3 \boldsymbol{K} t)+\boldsymbol{A}^{2} \cos (5 \boldsymbol{K} t)\right]}{384\left[120 \mathbf{w}^{2}+\boldsymbol{\alpha}^{2}\left(120+20 \boldsymbol{A}^{2}+\boldsymbol{A}^{4}\right)\right]} .
$$

Thus, we obtain the first-order approximation by setting $p=1$

$$
u=u_{0}+u_{1}=A \cos (K t)
$$

$$
\left.+\frac{\boldsymbol{\alpha}^{2} \boldsymbol{A}^{3}\left[-16\left(\boldsymbol{A}^{2}-15\right) \cos (\boldsymbol{K} t)+15\left(\boldsymbol{A}^{2}-16\right) \cos (3 \boldsymbol{K} t)+\boldsymbol{A}^{2} \cos (5 K \boldsymbol{t})\right]}{384\left[120 \boldsymbol{w}^{2}+\boldsymbol{\alpha}^{2}\left(120+20 \boldsymbol{A}^{2}+\boldsymbol{A}^{4}\right)\right]} t\right) .
$$

The first-order approximate solution of HPM of the problem may be obtained as

$u=A \cos (w t)+\frac{A^{3} \alpha^{2}}{46080}\left[-16\left(A^{2}-15\right) \cos (\omega t)+15\left(A^{2}-16\right) \cos (3 \omega t)+A^{2} \cos (5 \omega t)\right]$.

We have made the numerical calculations of the solutions (26) and (27) for distinct $t$ values and $\boldsymbol{A}=5, \boldsymbol{\alpha}=3$. Figure 1 shows the comparison of the solutions for distinct $t$ values. It is clear that in HPM, the difference between zero-order and the 1st order solutions diverges when $t$ gets larger. But, zero-order and the 1 st order solutions for MHPM are consistent even for large $t$ values. This distinction is clearly observed on Figure 1 and Figure 2 for HPM and MHPM respectively. Therefore, MHPM works better in comparison with HPM.

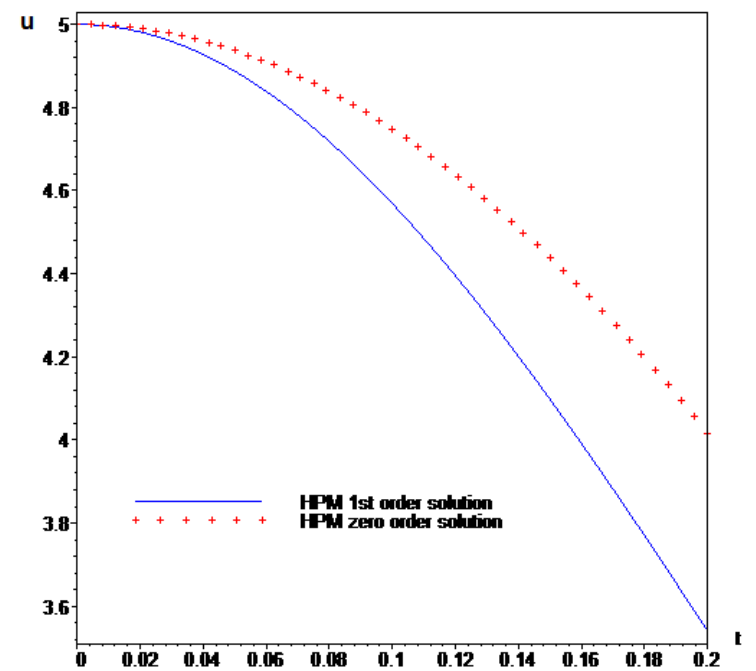

Figure 1. The comparison between zero-order and the 1st order solutions for HPM and

$$
\boldsymbol{A}=5, \boldsymbol{\alpha}=3 \text {. }
$$

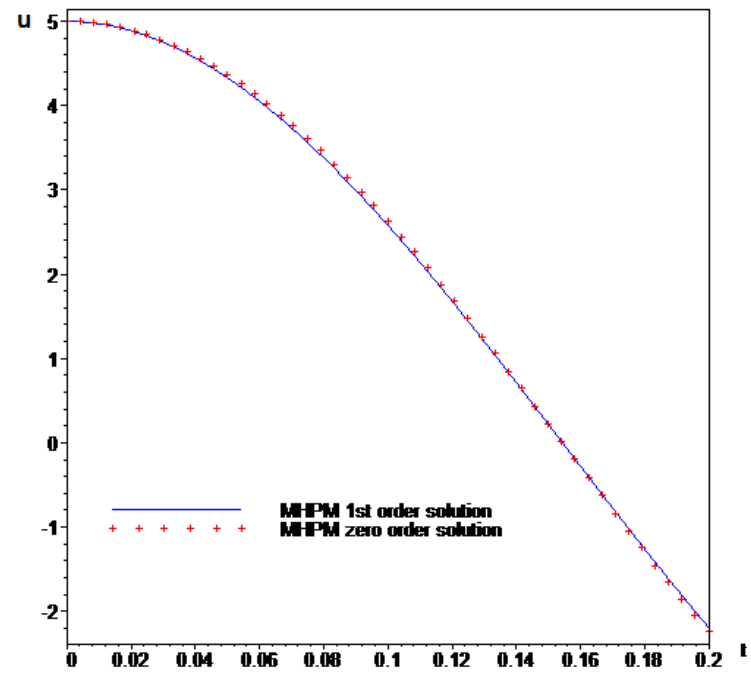

Figure 2. The comparison between zero-order and the 1st order for solutions for MHPM for and

$$
\boldsymbol{A}=5, \boldsymbol{\alpha}=3 \text {. }
$$

\section{DISCUSIONS, CONCLUSION AND RECOMMENDATIONS}

In this paper, we used the modification form of HPM and showed the effectiveness of the modification. The modified form of HPM is more accurate than the standard HPM for nonlinear oscillators. This method can be applied efficiently for nonlinear oscillators. 


\section{REFERENCES}

1. He, J.H., (1999). Homotopy Perturbation Technique. Comput. Methods Appl. Mech. Eng., 178, 3-4 257-262. http://dx.doi.org/10.1016/S0045-7825(99)00018-3

2. He, J.H., (2003). Homotopy Perturbation Method: A New Nonlinear Analytical Technique. Applied Mathematics and Computation. 135, 1, 73-79. http://dx.doi.org/10.1016/S0096-3003(01)00312-5.

3. Babolian, E., Saeidian, J., and Azizi, A., (2009). Application of Homotopy Perturbation Method to Some Nonlinear Problems. Applied Mathematical Sciences, 3, 45, 2215-2226. http://www.mhikari.com/ams/ams-password-2009/ams-password45-482009/saeidianAMS 4-48-2009.pdf.

4. He, J.H., (2004). The Homotopy Perturbation Method for Nonlinear Oscillators with Discontinuities. Applied Mathematics and Computation. 151, 1, 287-292. http://dx.doi.org/10.1016/s0096$3003(03) 00341-2$.

5. He, J.H., (2006). New Interpretation of Homotopy Perturbation Method. International Journal of Modern Physics B, 20:2561-2568.

6. Rafei, M., Ganji, D.D., Daniali, H.R.M., and Pashaei, H., (2007). Application of Homotopy Perturbation Method to The RLW and Generalized Modified Boussinesq Equations. Physics Letters A, 364, 1, 1-6.dx.doi.org/10.1016/j.physleta.2006.11.047.

7. Aminikhaha, H. and Hemmatnezhad, M., (2011). An Effective Modification of The Homotopy Perturbation Method for Stiff Systems of Ordinary Differential Equations. Appl Math Lett., 24, 9, 1502-1508.dx.doi.org/10.1016/j.aml.2011.03.032.

8. Akindeinde, S.O., (2015). Homotopy Perturbation Method for The Strongly Nonlinear Darcy-Forscheimer Model. Math Theor Model., $5,9,78-84$. www. iiste.org/Journals/index.php/MTM/article/viewFile.

9. Abdur Razzak, M.D. and Shamsul Alam, M.D., (2016). An Analytical Coupled Technique for Solving Nonlinear LargeAmplitude Oscillation of A Conservative System with Inertia and Static Non-Linearity. 5: 456, doi:10.1186/s40064-016-2089-5.

10. Wang, S.Q. and He, J.H., (2008). Nonlinear Oscillator with Discontinuity by Parameter-Expansion Method. Chaos, Solutions and Fractals, 35, 4, 688-691. http://dx.doi.org/10.1016/j.chaos.2007.07.055.

11. Xu, L., (2007). He's Parameter-Expanding Methods for strongly Nonlinear Oscillators, Journal of Computational and Applied Mathematics. 207, 1, 148-154. http://dx.doi.org/10.1016/j.cam.2006.07.020

12. He, J.H., (1999). Variational Iteration Method-A Kind of NonLinear Analytical Technique: Some Examples. International Journal of Non-Linear Mechanics, 34, 4, 699-708. doi:10.1016/S0020-7462(98)00048-1.

13. Ramos, J.I., (2008). On the Variational Iteration Method and Other Iterative Techniques for Nonlinear Differential Equations. Applied Mathematics and Computation. 199, 39-69.

14. Liu, H.M., (2005). Approximate period of nonlinear oscillators with discontinuities by modified Lindstedt-Poincare method. Chaos, Solitons and Fractals. 23, 2, 577-579. http://dx.doi.org/10.1016/j.chaos.2004.05.004.

15. Beléndez, A., Gimeno, E., Fernández, E., Méndez, D.I., and Alvarez, M., (2008). Accurate Approximate Solution to Nonlinear Oscillators in which the Restoring Force is Inversely Proportional to the Dependent Variable. Phys. Scr., doi:10.1088/0031-8949/77/06/065004. 
16. Faydaoglu, Ş. and Öziş, T., (2009). Soliton Solution of the Boussinesq Equation by The Modified Decomposition Method. World Applied Sciences Journal (WASJ), IDOSI, 7, 5, 600-609. http://www.idosi.org/wasj/wasj7 (5)/7.pdf.

17. He, J.H., (2002). Preliminary Report on The Energy Balance for Nonlinear Oscillations. Mechanics research communications, 29, 2-3, 107-111. http://dx.doi.org/10.1016/S0093-6413(02)00237-9.

18. Khan Najeeb, A., Ara, A., and Khan Naadem, Alan., (2014). On Solutions of the Nonlinear Oscillators by Modified Homotopy Perturbation Method. Mathematical Sciences Letters, 3, 3, $229-$ 236. www.naturalspublishing.com/files/published/28274pw 72 unx27.

19. Ganji, D.D., Sahouli, A.R., and Famouri, M.A., (2009). A new modification of He's homotopy perturbation method for rapid convergence of nonlinear undamped oscillators. J Appl Math Comput 30, 1, 181-192. doi:10.1007/s12190-008-0165-x.

20. Jin, L., (2010). Application of the Modified Homotopy Perturbation Method to the Two Dimensional sine-Gordon Equation. Int. J. Contemp. Math. Sciences, 5, 20, 985-990. http://www.mhikari.com/ijcms-2010/17-20-2010/linjinIJCMS17-20-2010.pdf.

21. Panda, S., (2013). Assessment of Homotopy Analysis Method and Modified Homotopy Perturbation Method for Strongly Nonlinear Oscillator. International Journal of Nonlinear Science, 16, 4, 291-300.

22. Suleman, M. and Wu, Q., (2015). Comparative solution of nonlinear quintic cubic oscillator using modified homotopy perturbation method. Adv Math Phys. http://dx.doi.org/10.1155/2015/932905.

23. Wang, F., Li, W., and Zhang, H., (2012). A New Extended Homotopy Perturbation Method for Nonlinear Differential Equations. Math Comput Model., 55, 3-4, 1471-1477. http://dx.doi.org/10.1016/j.mcm.2011.10.029.

24. Çelik, A., (2016). A Note on the Growth of Polynomials. Physical Sciences, ISSN: 13087304 (NWSAPS), ID: 2016.11.2.3A0076, http://dx.doi.org/10.12739/NWSA.2016.11.2.3A0076. 